\title{
Dissociation of Basic Dyes by Advanced Oxidation: Theoretical Study by DFT Calculations
}

\author{
ABDELKADER M. ELHORRI ${ }^{* 1}$ and MOURAD ZOUAOUI RABAH ${ }^{2}$ \\ ${ }^{1}$ Department of Chemistry, Faculty of Exact Sciences and Informatics, Hassiba BenBouali \\ University of Chlef, P.O. Box 78C, Ouled Fares Chlef 02180, Algeria \\ ${ }^{2}$ Department of Chemistry, faculty of exact sciences, Djillali Liabes University of Sidi-Bel- \\ Abbes, P.O. Box 89, 22000 Sidi Bel-Abbes, Algeria
}

Received 8 September 2018 / Accepted 3 October 2018

\begin{abstract}
This work is based on a theoretical study concerning the degradation of basic dyes by advanced oxidation on five basic molecules called as follows: basic red 2 (BR2), basic red 5 (BR5), basic red (BR10), basic violet 5 (BV5) and basic violet 12 (BV12). The purpose of this work is to determine the attack sites most reactive to radical attacks. In other words, the location of the sites which favors the degradation by using the advanced oxidation process. This process is essential in the field of the water depollution. The work was done theoretically by ab initio methods. The calculations were carried out by CAM-B3LYP functional and $6-31++G(d, p)$ basis set. The exploitation of the results gives the following parameters: local indices of reactivities to radical attacks, global indices of reactivities and transition states. The results obtained from these parameters show the most reactive sites to radical attacks that are in good agreement with the sites determined experimentally. Hence, the majority of the sites were located at the level of the phenazine chromophore constituting the five dyes.
\end{abstract}

Keywords: Basic dyes, Advanced oxidation, Radical attacks, Fukui indices, DFT, TD-DFT

\section{Introduction}

Textile dyes have wide applications in the fields of textile industry, paper industry, agrofood $^{1}$, medicinal and photovoltaic ${ }^{2,3}$. One of the families of textile dyes is the family of basic dyes used in the textile industry. These dyes are characterized by good resistance and chemical stability ${ }^{4}$, they are also resistant to light, high temperature (heat) and oxidizing agents ${ }^{5}$. The resistance of basic dyes to the processes of advanced oxidation is due to the electron-acceptor groups forming part of their backbones ${ }^{6}$. It is for this reason that these dyes are considered as non-biodegradable molecules ${ }^{7}$. The non-biodegradability of basic dyes is dangerous for the environment. Knowing that, these dyes are unloaded by textile industries in river waters and soils ${ }^{8}$. However, researchers have developed methods for the removal of textile dyes such as adsorption, coagulation-flocculation, electrocoagulation, flotation, chemical oxidation, advanced oxidation, ozonation and photo-catalysis ... etc ${ }^{9-13}$. 
The advanced oxidation was largely studied by the researchers in order to eliminate the basic dyes in the waste water, this process has the principle of generating intermediate species which are the hydroxyl radicals ${ }^{\bullet} \mathrm{OH}$, these species are generated by the dissociation of the hydrogen peroxide in the presence of metal Fe(II) or UV light ${ }^{14}$. The elimination of textile dyes by the method mentioned above leads to the formation of the following compounds: water $\mathrm{H}_{2} \mathrm{O}$ and carbon dioxide ${ }^{15,16} \mathrm{CO}_{2}$. Advanced oxidation is important for increasing the biodegradability of pollutants and for its low cost ${ }^{17,18}$.

In this context, we will mention some works on basic dyes elimination of by advanced oxidation process while explaining the parameters influencing the profitability of the elimination. In addition, we will mention some dissociation mechanisms of basic dyes proposed by the researchers. Fathy et al. conducted an experimental study on the removal of basic red 18 by catalyzed oxidation. Hence, they recorded optimal profitability at a near neutral $\mathrm{pH}$. The corresponding elimination mechanism led to the formation of the following products: carbon dioxide $\mathrm{CO}_{2}$, water $\mathrm{H}_{2} \mathrm{O}$, nitric acid $\mathrm{HNO}_{3}$ and chlorine ${ }^{19}$ gas $\mathrm{Cl}_{2}$. Another mechanism has been proposed by Siwinska-Stefańska et al. Demonstrates that basic blue 9 and basic red 1 dyes elimination in presence of the two radicals $\mathrm{O}_{2}^{\bullet-}$ and ${ }^{\bullet} \mathrm{OH}$ results the formation of the following compounds: Carbon dioxide $\mathrm{CO}_{2}$ and water $\mathrm{H}_{2} \mathrm{O}$ for the first radical, the same products were obtained with the second radical but with other products in addition $^{20}$. Hassani et al. conducted a similar study on the removal of basic violet (BV10) at an optimal acid $\mathrm{pH}$. The radicals obtained from the degradation of oxygenated water were ${ }^{\bullet} \mathrm{OH}, \mathrm{O}_{2}^{-}$and $\mathrm{HO}_{2}$, But the most abundant radicals was hydroxyls ${ }^{21}$. Singh et al. conducted an experimental study on methylene blue degradation by advanced oxidation. The corresponding mass spectroscopy spectrum revealed that the hydroxyl radicals attacks were concentrated on the three double bonds $\mathrm{C}=\mathrm{C}$ and $\mathrm{C}=\mathrm{N}$ above the suffer atom in order to break the cycle $^{22}$. Another study carried out by Tokeer Ahmed on methylene blue photodegradation in the presence of the catalyst $\mathrm{CuCrO}_{2}$ nanoparticle; shows that the mechanism of degradation is based on the $\mathrm{C}=\mathrm{C}$ double bonds destruction constituent the two benzene rings at the ends ${ }^{23}$. The same mechanisms have been proposed to methylene blue photodegradation by the $\mathrm{TiO}_{2}-\mathrm{Cu}$ catalyst thin films ${ }^{24}$ and vanadium-doped iron oxides nanostructured $^{25}$. On the other hand, other studies show that the basic dye photodegradation mentioned before begins with the opening of the cycle which is in the middle. The latter is constituted by the heteroatoms ${ }^{26-28} \mathrm{~N}$ and $\mathrm{S}$.

In the light of this bibliography we conclude that basic dyes degradation leads to the formation of several products which are depending on dyes nature of. In addition, three types of mechanisms have been proposed by researchers for the degradation of basic dyes by advanced oxidation.

In this article we will discuss a theoretical study of five basic dyes degradation (Figure 1) by advanced oxidation. Our objective is to determine the reactive sites by radical attacks in order to determine the preliminary degradation mechanism and to make a comparison with the mechanisms obtained experimentally. This study is carried out theoretically by ab initio methods. The originality of our article is based on the determination of the preliminary mechanisms of dyes degradation mentioned before accompanied by a study concerning the parameters influencing the profitability of degradation.

\section{Computational details}

All calculations were carried out by NWChem 6.6 program open source ${ }^{29}$. Hence, our work has focused on the study of five basic dyes: basic red 2 (BR2), basic red 5 (BR5), basic 
red 10 (BR10), basic violet 5 (BV5) and basic violet (BV12). We chose these dyes because they include the phenazine chromophore in common but the grafted radicals are different. Where, radical variation influences the efficiency of degradation by advanced oxidation. First, we calculated dyes geometries by optimizations performed by the long range corrected version of B3LYP using the coulomb-attenuating method CAM-B3LYP functional ${ }^{30}$ combined with the $6-31++\mathrm{G}(\mathrm{d}, \mathrm{p})$ basis set in the presence of the solvent water using the solvation model cosmo polarizable continuum model $\mathrm{CPCM}^{31,32}$. Knowing that the studied dyes are conjugated and charged systems and their eliminations is done in water solvent, it is for this reason that we have chosen the functional and the base mentioned before because they are more descriptive of the electronic parameters according to previous work ${ }^{33-37}$. The geometries obtained were subjected to single point SP calculations in order to calculate the following parameters: total dipole moments in solution $\mu_{\text {tot }}$, hardnesses $\eta$, chemical potentials $\mu$, electronegativities $\chi$ and solvation Gibbs free energies $\Delta \mathrm{G}_{\text {solv }}$ calculated by SMD solvation mode ${ }^{38}$. We also calculated the local reactivity indices $f_{k}^{0}$ obtained by

Fukui function for radical attacks. Finally, we have exploited electronic excitations parameters by time dependant functional density method TD-DFT ${ }^{39,40}$, in order to determine the maximum wavelengths $\lambda_{\max }$, dipole oscillator strengths $f$ and excitations energies $\Delta \mathrm{E}_{\text {Homo-Lumo. }}$

The total dipole moments ${ }^{41}$ are expressed by the following equation:

$$
\mu=\sqrt{\left(\mu_{x}^{2}+\mu_{y}^{2}+\mu_{z}^{2}\right)}
$$

The electronic chemical potentials $\mu$, the electronegativities $\chi$ and the overall hardnesses $\eta$ can be calculated from the energies of frontier molecular orbitals $\varepsilon_{\text {HOMO }}$ and $\varepsilon_{\text {LUMO }}$ as follows ${ }^{42,43}$ :

$$
\begin{aligned}
& \mu=-\left(_{\text {Hомо }}+{ }_{\text {LUMO }}\right) / 2 \\
& \mu=\left({ }_{\text {Hомо }}-_{\text {LUMO }}\right)
\end{aligned}
$$

Local reactivity indices ${ }^{44-46} f_{k}^{0}$ obtained by Fukui function for radical attacks are expressed by the following equation:

$$
f_{k}^{0}=\left[q_{k}(N+1)-q_{k}(N-1) / 2\right]
$$

Where, $q_{k}(N+1)$ : electronic population of the atom $\mathrm{k}$ in the anionic molecule. $q_{k}(N-1)$ : electronic population of the atom $\mathrm{k}$ in the canionic molecule.

In the NWChem 6.6 program the parameters of the global reactivity hardnesses $\eta$, chemical potentials $\mu$ and electronegativities $\chi$ are given directly in the output file. The parameters of the local reactivity $q_{k}(N+1)$ et $q_{k}(N-1)$ are expressed by other indices in this program which are: $f_{n n}^{+}$et $f_{n n}^{-}$respectively.

\section{Analysis of global reactivity indices}

Table 1 summarizes the results of hardnesses $\eta$, chemical potentials $\mu$, electronegativities $\chi$, dipole moment elements $\mu_{\mathrm{x}}, \mu_{\mathrm{y}}, \mu_{\mathrm{z}}$, total dipole moments $\mu_{\mathrm{tot}}$ and solvation Gibbs free energies $\Delta \mathrm{G}_{\text {solv }}$. These parameters are calculated by CAM-B3LYP functional and the base $6-31++\mathrm{G}(\mathrm{d}, \mathrm{p})$ in the presence of water solvent using the implicit solvation model CPCM. The corresponding calculations were performed on the five basic dyes BR2, BR5, BR10, BV5 and BV12 (Figure 1). 
Table 1. Hardnesses $\eta$. chemical potentials $\mu$ and electronegativities $\chi$ in (eV). Mean dipole moments $\mu_{\mathrm{x}}, \mu_{\mathrm{y}}, \mu_{\mathrm{z}}$ and total dipole moments $\mu_{\mathrm{tot}}$ in (Debye). Solvation Gibbs free energies $\Delta \mathrm{G}_{\mathrm{solv}}$ in kcal.mol ${ }^{-1}$ of the five dyes calculated by the CAM-B3LYP/6-31++G(d. p) in the presence of water solvent by the implicit solvation model CPCM

\begin{tabular}{llll}
\hline & $\eta$ & $\mu$ & $\chi$ \\
\hline $\mathrm{BR} 2$ & 4.77 & -4.71 & 4.71 \\
$\mathrm{BR} 5$ & 4.64 & -4.63 & 4.63 \\
$\mathrm{BR} 10$ & 4.67 & -4.60 & 4.60 \\
$\mathrm{BV5}$ & 4.63 & -4.69 & 4.69 \\
$\mathrm{BV} 12$ & 4.75 & -4.70 & 4.70
\end{tabular}

$\mathrm{BR} 2$

$\begin{array}{lllcc}\mu_{\mathrm{x}} & \mu_{\mathrm{y}} & \mu_{\mathrm{z}} & \mu_{\text {tot }} & \Delta \mathrm{G}_{\text {solv }} \\ 0.00 & 0.00 & 3.61 & 3.61 & -44.45 \\ 6.90 & 0.48 & 0.00 & 6.92 & -48.34 \\ 3.36 & 1.00 & 0.00 & 3.51 & -40.31 \\ 3.02 & 0.92 & 0.00 & 3.16 & -42.25 \\ 2.95 & 3.94 & 0.00 & 4.92 & -42.82\end{array}$<smiles></smiles>

BR10<smiles></smiles>

BR5<smiles>CN(C)c1ccc2nc3ccc(N)cc3[n+](C3=CCC=CC3)c2c1</smiles>

BV5<smiles></smiles>

BV12

Figure 1. Molecules studied in this article

The first parameter of the hardness $\eta$ is very important for the description of the molecular stability, knowing that the hardness is proportional to the molecular stability ${ }^{47}$. However, the descending order of the basic dye hardnesses is as follows: $\eta($ BR2) $>\eta(B V 12)>\eta(B R 10)>$ $\eta(B R 5)>\eta$ (BV5). From the point of view of molecular stability we will record the same descending order obtained before. Knowing that, the five dyes are made of the same phenazine chromophore. Therefore, the hardnesses and the corresponding stabilities are influenced by the groups grafted onto the phenazine skeleton. The BR2 dye has recorded the highest hardness; this phenomenon can be explained by the corresponding molecular symmetry. We have also noticed that each addition of a benzene or alkyl group increases the molecular stability. The BV12 dye has two benzene groups and two methyl groups, the BR 
10 dye has a single benzene group and two methyl groups, the BR5 dye has a single methyl group and the BV5 dye a has single benzene group. From these remarks it is deduced that the molecular stability in this type of system is influenced by the symmetry and the benzene and alkyl groups grafted on the phenazine chromophore.

The electronegativity parameters $\chi$ show the following descending order: $\chi$ (BR2) $>\chi$ $(\mathrm{BV} 12)>\chi(\mathrm{BV} 5)>\chi(\mathrm{BR} 5)>\chi(\mathrm{BR} 10)$. The BR2 molecule has the highest electronegativity. This phenomenon may be explained by the fact that the positive charge of nitrogen is slightly influenced by the four methyl and amine groups because the molecule is symmetrical. It is for this reason that the latter has given the highest positive charge. In this case, the BV12 molecule recorded a value almost identical to that of the BR2 molecule. This phenomenon can be explained by the fact that this molecule varies from the molecule BR2 by a phenyl group grafted on the amine which is on the right. The last three remaining molecules gave the lowest values of electronegativities. In this type of system we notice that the parameters $\chi$ decrease when the donor groups increase. Knowing that the BV5 molecule has two amine and dimethylamine donor groups, the second molecule BR5 has three groups: amine, dimethylamine and methyl, the last molecule BR10 has four groups: methylamine, ethylamine and two methyl. Therefore, the donor groups mentioned earlier may have the tendency to weaken the positive charge centered on the nitrogen atom. This phenomenon generates the decrease of the electronegativities. From these remarks it is deduced that the electronegativities of the dyes studied are influenced by the positive charge strength centered on the nitrogen atom. The latter is influenced by the number and strength of donor groups grafted onto the phenazine skeleton.

The same remarks were recorded for the parameters of the chemical potentials $\mu$ since these parameters are inversely proportional to the electronegativities. The total dipole moments exploitation indicates that the three BR2, BR10 and BV5 molecules give values in the range of 3.16 to 3.61 Debye. On the other hand, the two remaining molecules BR5 and BV12 gave higher values with deviations in the range of 1.5 to 3.5 Debye. This phenomenon can be explained by the fact that the first three molecules are planar in the XY axes but the other molecules are three-dimensional in the XYZ axes because of the dimethyl groups grafted on the amine nitrogen in the BR5 molecule and the phenyl which is found right in the BV12 molecule. Knowing that, these two groups are out of the XY plane. From which we deduce that the total dipole moments of the studied molecules are influenced by the groups located outside the XY plane.

Finally, the solvation Gibbs free energies record the following decreasing order: $\Delta \mathrm{G}_{\text {solv }}$ $\left(\right.$ BR10) $>\Delta \mathrm{G}_{\text {solv }}\left(\right.$ BV5) $>\Delta \mathrm{G}_{\text {solv }}\left(\right.$ BV12) $>\Delta \mathrm{G}_{\text {solv }}\left(\right.$ BR2) $>\Delta \mathrm{G}_{\text {solv }}$ (BR5). Knowing that, the molecules with the lowest values of $\Delta \mathrm{G}_{\text {solv }}$ are the most solvated in water. Therefore, the two most solvated molecules in water are BR2 and BR5 and the least solvated molecules in water are BR10, BV5 and BV12. In this context, the difference between the first series composed by BR2 and BR5 molecules the second series composed by BR10, BV5 and BV12 molecules; it is because that the first series is characterized by a low number of methyl groups grafted on the phenazine chromophore and on the amines. On the other hand, the second series is characterized by a high number of methyl and ethyl groups in BR10 molecule. From these observations, it is deduced that the solvation of these molecules in water is influenced by the number of alkyl groups grafted onto the phenazine chromophore and the amines.

In summary, the stabilities of the molecules studied are influenced by the symmetry, the benzene and alkyl groups grafted onto the phenazine chromophore. The corresponding electronegativities are influenced by the strength of the positive charge centered on the nitrogen 
atom which is in turn influenced by the number and strength of donor groups grafted onto the phenazine backbone. The chemical potentials $\mu$ revealed the same deductions because of their inverse proportionality with the electronegativities. The total dipole moments of the studied molecules are influenced by the groups located outside the XY plane. Finally, the solvation of these molecules is influenced by the number of alkyl groups grafted onto the phenazine chromophore and the amines.

\section{Analysis of local reactivity indices}

Table 2 summarizes Fukui indices results $f_{k}^{0}$ for each molecule (see eq. 4). These indices indicate the effect of radical attacks on the molecules studied. We calculated the indices cited above by the CAM-B3LYP functional combined with the $6-31++\mathrm{G}(\mathrm{d}, \mathrm{p})$ basis-set in the presence of the water solvent using the CPCM solvation model. We have also reported on the Table 2. The Fukui indices barriers $\Delta f_{k}^{0}$ in order to valorize the effectiveness of radical attacks on each molecule, these parameters are expressed by the following equation ${ }^{34}$ :

$$
\Delta f_{k}^{0}=f_{k}^{0}(\max )-f_{k}^{0}(\min )
$$

Avec $f_{k}^{0}(\max )$ is the highest value theoretically obtained. Avec $f_{k}^{0}(\max )$ is the lowest value obtained theoretically. $\Delta f_{k}^{0}$ Is the barrier of the Fukui index between the highest and the lowest values.

Table 2. Fukui indices of all atoms dyes obtained from Mulliken charges calculated by CAM-B3LYP/6-31++G(d, p) in the presence of water solvent by the CPCM implicit solvation model

\begin{tabular}{|c|c|c|c|c|c|c|c|c|c|}
\hline \multicolumn{2}{|c|}{ BR2 } & \multicolumn{2}{|c|}{ BR5 } & \multicolumn{2}{|c|}{ BR10 } & \multicolumn{2}{|c|}{ BV5 } & \multicolumn{2}{|c|}{ BV12 } \\
\hline Atoms & $f_{k}^{0}$ & Atoms & $f_{k}^{0}$ & Atoms & $f_{k}^{0}$ & Atoms & $f_{k}^{0}$ & Atoms & $f_{k}^{0}$ \\
\hline N1 & 0.03815 & $\mathrm{C} 1$ & -0.00095 & N1 & 0.03905 & C1 & -0.01490 & N1 & 0.03855 \\
\hline $\mathrm{N} 2$ & 0.10350 & $\mathrm{C} 2$ & -0.01740 & $\mathrm{~N} 2$ & 0.10375 & $\mathrm{C} 2$ & 0.03825 & N2 & 0.10390 \\
\hline N3 & -0.04625 & C3 & 0.03450 & N3 & -0.04935 & $\mathrm{C} 3$ & -0.04955 & N3 & -0.04525 \\
\hline $\mathrm{N} 4$ & -0.04625 & $\mathrm{C} 4$ & -0.03885 & N4 & -0.04925 & N4 & 0.10430 & N4 & -0.05010 \\
\hline C5 & 0.03505 & N5 & 0.10405 & $\mathrm{C} 5$ & 0.03770 & $\mathrm{C} 5$ & -0.04545 & $\mathrm{C} 5$ & 0.03545 \\
\hline C6 & 0.03505 & C6 & -0.03865 & C6 & 0.03780 & C6 & 0.03890 & C6 & 0.03630 \\
\hline C7 & -0.05270 & $\mathrm{C} 7$ & 0.03590 & $\mathrm{C} 7$ & -0.04735 & $\mathrm{C} 7$ & -0.01175 & $\mathrm{C} 7$ & -0.05090 \\
\hline $\mathrm{C} 8$ & -0.05270 & $\mathrm{C} 8$ & -0.00755 & $\mathrm{C} 8$ & -0.04725 & $\mathrm{C} 8$ & 0.02260 & $\mathrm{C} 8$ & -0.05075 \\
\hline C9 & 0.01100 & C9 & 0.01500 & C9 & 0.00710 & N9 & -0.07380 & $\mathrm{C} 9$ & 0.01200 \\
\hline $\mathrm{C} 10$ & -0.03350 & N10 & -0.08010 & $\mathrm{C} 10$ & -0.03785 & $\mathrm{C} 10$ & -0.00470 & $\mathrm{C} 10$ & -0.03280 \\
\hline $\mathrm{C} 11$ & -0.03350 & C11 & -0.00475 & $\mathrm{C} 11$ & -0.03735 & $\mathrm{C} 11$ & -0.00365 & $\mathrm{C} 11$ & -0.03310 \\
\hline $\mathrm{C} 12$ & 0.03745 & $\mathrm{C} 12$ & -0.00460 & C12 & 0.03425 & $\mathrm{C} 12$ & -0.0 & $\mathrm{C} 12$ & 0.03740 \\
\hline $\mathrm{C} 13$ & 0.03745 & $\mathrm{C} 13$ & -0.06025 & $\mathrm{C} 13$ & 0.03395 & $\mathrm{C} 13$ & 0.03840 & $\mathrm{C} 13$ & 0.03420 \\
\hline C14 & -0.01920 & C14 & 0.03090 & C14 & -0.01750 & N14 & 0.03450 & $\mathrm{C} 14$ & -0.01750 \\
\hline C15 & -0.01920 & N15 & 0.03945 & C15 & -0.01715 & C15 & 0.03160 & $\mathrm{C} 15$ & -0.01785 \\
\hline C16 & 0.01035 & H16 & 0.00035 & C16 & 0.01650 & $\mathrm{C} 16$ & -0.01865 & C16 & 0.01045 \\
\hline $\mathrm{C} 17$ & 0.01035 & $\mathrm{C} 17$ & 0.02715 & $\mathrm{C} 17$ & 0.01610 & $\mathrm{C} 17$ & 0.01620 & $\mathrm{C} 17$ & 0.01070 \\
\hline C18 & 0.00165 & $\mathrm{C} 18$ & -0.01175 & C18 & -0.00085 & N18 & -0.03055 & C18 & 0.00120 \\
\hline C19 & 0.00165 & C19 & 0.01705 & C19 & -0.00085 & H19 & 0.00015 & C19 & 0.00120 \\
\hline $\mathrm{C} 20$ & -0.00135 & N20 & -0.02365 & $\mathrm{C} 20$ & -0.00105 & $\mathrm{H} 20$ & -0.00005 & $\mathrm{C} 20$ & -0.00135 \\
\hline C21 & -0.00135 & H21 & 0.00000 & $\mathrm{C} 21$ & -0.00095 & $\mathrm{H} 21$ & -0.00020 & $\mathrm{C} 21$ & -0.00120 \\
\hline
\end{tabular}




\begin{tabular}{|c|c|c|c|c|c|c|c|c|c|}
\hline $\mathrm{C} 22$ & -0.00555 & H22 & -0.00055 & $\mathrm{C} 22$ & -0.00125 & $\mathrm{H} 22$ & 0.00015 & $\mathrm{C} 22$ & -0.00530 \\
\hline $\mathrm{C} 23$ & -0.00555 & $\mathrm{H} 23$ & -0.00055 & $\mathrm{C} 23$ & -0.00125 & $\mathrm{H} 23$ & 0.00000 & $\mathrm{C} 23$ & -0.00530 \\
\hline C24 & -0.00325 & $\mathrm{H} 24$ & 0.00010 & $\mathrm{C} 24$ & -0.00130 & $\mathrm{H} 24$ & -0.00360 & $\mathrm{C} 24$ & -0.00320 \\
\hline $\mathrm{H} 25$ & -0.00010 & $\mathrm{H} 25$ & -0.00005 & $\mathrm{H} 25$ & -0.00015 & $\mathrm{H} 25$ & -0.00360 & $\mathrm{H} 25$ & -0.00010 \\
\hline H26 & -0.00010 & $\mathrm{H} 26$ & -0.00020 & H 26 & -0.00015 & $\mathrm{H} 26$ & 0.00000 & $\mathrm{H} 26$ & -0.00010 \\
\hline $\mathrm{H} 27$ & 0.00010 & H27 & 0.00015 & H27 & 0.00010 & H27 & -0.00320 & $\mathrm{H} 27$ & 0.00010 \\
\hline $\mathrm{H} 28$ & 0.00010 & $\mathrm{H} 28$ & 0.00000 & $\mathrm{H} 28$ & 0.00010 & $\mathrm{H} 28$ & -0.00320 & $\mathrm{H} 28$ & 0.00010 \\
\hline H29 & 0.00030 & $\mathrm{H} 29$ & -0.00365 & H 29 & 0.00000 & $\mathrm{H} 29$ & -0.00010 & $\mathrm{H} 29$ & 0.00020 \\
\hline H30 & 0.00030 & H30 & -0.00365 & $\mathrm{H} 30$ & 0.00000 & H30 & -0.00015 & H30 & 0.00020 \\
\hline H31 & 0.00000 & H31 & 0.00000 & H31 & 0.00000 & H31 & -0.00005 & H31 & 0.00000 \\
\hline H32 & -0.00035 & H32 & -0.00365 & H32 & -0.00030 & $\mathrm{H} 32$ & 0.00000 & H32 & -0.00025 \\
\hline H33 & -0.00035 & H33 & -0.00365 & H33 & -0.00030 & C33 & 0.00745 & H33 & -0.00025 \\
\hline H34 & -0.00035 & H34 & -0.00010 & H34 & -0.00035 & C34 & 0.00040 & H34 & -0.00060 \\
\hline H35 & -0.00035 & H35 & -0.00010 & H35 & -0.00035 & $\mathrm{C} 35$ & 0.00040 & H35 & -0.00060 \\
\hline H36 & 0.00000 & H36 & 0.00005 & H36 & 0.00000 & C36 & -0.00280 & H36 & 0.00000 \\
\hline H37 & 0.00015 & - & - & H37 & 0.00005 & H37 & 0.00000 & H37 & 0.00010 \\
\hline H38 & 0.00015 & - & - & H38 & 0.00005 & C38 & -0.00280 & H38 & 0.00010 \\
\hline H39 & -0.00020 & - & - & H39 & -0.00025 & H39 & 0.00000 & H39 & -0.00020 \\
\hline $\mathrm{H} 40$ & -0.00020 & - & - & $\mathrm{H} 40$ & -0.00025 & $\mathrm{C} 40$ & -0.00215 & $\mathrm{H} 40$ & -0.00030 \\
\hline H41 & -0.00020 & - & - & H41 & 0.00000 & $\mathrm{H} 41$ & 0.00005 & H41 & 0.00000 \\
\hline $\mathrm{H} 42$ & -0.00020 & - & - & $\mathrm{C} 42$ & -0.00230 & $\mathrm{H} 42$ & 0.00005 & $\mathrm{H} 42$ & -0.00020 \\
\hline H43 & 0.00000 & - & - & $\mathrm{H} 43$ & -0.00235 & $\mathrm{H} 43$ & 0.00000 & $\mathrm{C} 43$ & -0.00210 \\
\hline- & - & - & - & $\mathrm{H} 44$ & -0.00235 & - & - & $\mathrm{C} 44$ & -0.00175 \\
\hline- & - & - & - & $\mathrm{H} 45$ & 0.00000 & - & - & $\mathrm{C} 45$ & -0.00175 \\
\hline - & - & - & - & $\mathrm{C} 46$ & -0.00240 & - & - & $\mathrm{C} 46$ & 0.00065 \\
\hline- & - & - & - & $\mathrm{H} 47$ & -0.00225 & - & - & $\mathrm{H} 47$ & -0.00010 \\
\hline - & - & - & - & $\mathrm{H} 48$ & -0.00225 & - & - & $\mathrm{C} 48$ & 0.00065 \\
\hline - & - & - & - & $\mathrm{C} 49$ & -0.00005 & - & - & $\mathrm{H} 49$ & -0.00010 \\
\hline- & - & - & - & $\mathrm{H} 50$ & 0.00005 & - & - & $\mathrm{C} 50$ & -0.00025 \\
\hline- & - & - & - & H51 & 0.00000 & - & - & H51 & -0.00015 \\
\hline- & - & - & - & H52 & 0.00005 & - & - & H52 & -0.00015 \\
\hline- & - & - & - & - & - & - & - & H53 & 0.00000 \\
\hline$\Delta f_{k}^{0}$ & 0.15620 & $\Delta f_{k}^{0}$ & 0.18415 & $\Delta f_{k}^{0}$ & 0.15310 & $\Delta f_{k}^{0}$ & 0.17810 & $\Delta f_{k}^{0}$ & 0.15480 \\
\hline
\end{tabular}

The atoms numbering on each molecule and the reproduction of the values $f_{k}^{0}$ by curves are shown in the Figure 2.

According to the Table 2, the barriers of the Fukui indices $\Delta f_{k}^{0}$ record the following descending order: $\Delta f_{k}^{0}(\mathrm{BR} 5)>\Delta f_{k}^{0}(\mathrm{BV} 5)>\Delta f_{k}^{0}(\mathrm{BV} 12)>\Delta f_{k}^{0}(\mathrm{BR} 2)>\Delta f_{k}^{0}$ (BR10). Knowing that $\Delta f_{k}^{0}$ parameter indicates the molecular trend to radical attacks taking into account the maximum values. For more information, we have plotted the representative curve of $\Delta f_{k}^{0}$ values as a function of the corresponding hardness which is reported in the Figure 2. The latter shows two series of molecules, series (a) composed of the two molecules BR5 and BV5, series (b) composed of the three molecules BR10, BR2 and BV12. We notice that the series (a) gave higher values than the series (b) from the parameter point of view $\Delta f_{k}^{0}$. In addition, the series (a) gave low values of hardness relative to the series (b). This phenomenon explains that the molecules with the weakest hardness (weak stability) 
are the most answered to radical attacks. We also plotted the representative curve of $\Delta f_{k}^{0}$ values as a function of the corresponding $\Delta \mathrm{G}_{\text {solv }}$ in the Figure 3. On this curve we only took the results of the BR2, BR5, BR10 and BV12 molecules. Hence, we record an inverse proportionality between the values $\Delta f_{k}^{0}$ as a function of $\Delta \mathrm{G}_{\text {solv }}$ with a regression coefficient in the order of 0.9984 . From these remarks, it is found that the degradation efficiency of these dyes is influenced by their solvations in the presence of water.

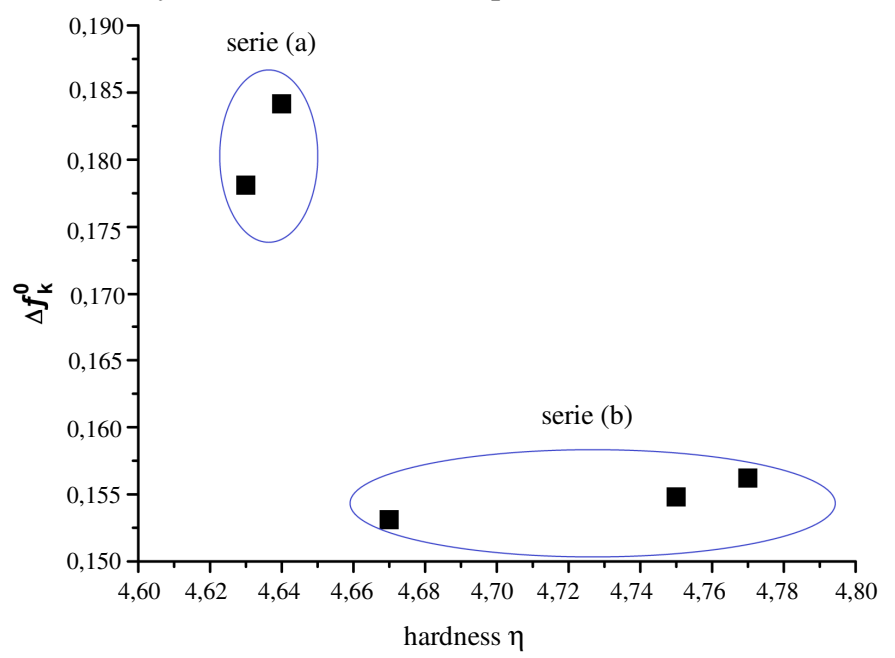

Figure 2. Relationship between Fukui indices $\Delta f_{k}^{0}$ and hardness $\eta$ of the five dyes studied calculated by the functional CAM-B3LYP combined with the basis-set $6-31++G(d, p)$ in the presence of water solvent by the implicit solvation model CPCM

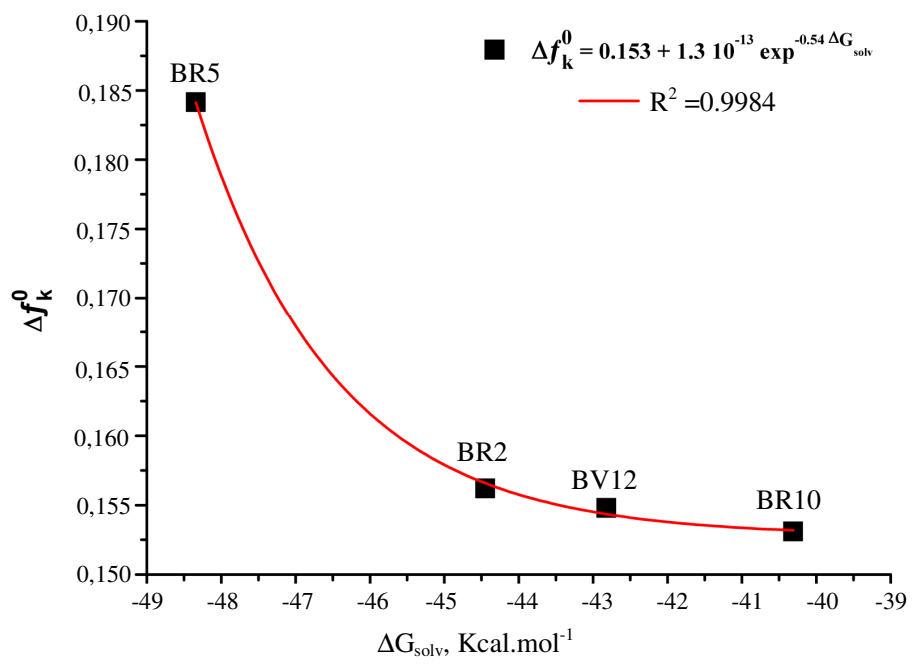

Figure 3. Relationship between Fukui indices $\Delta f_{k}^{0}$ and solvation Gibbs free energies $\Delta \mathrm{G}_{\text {solv }}$ of the four dyes BR2, BR5, BR10 and BV12 calculated by the functional CAM-B3LYP combined with the basis-set $6-31++\mathrm{G}(\mathrm{d}, \mathrm{p})$ in the presence of water solvent by the implicit solvation model CPCM 
From the Figure 4, we note that all the radical attacks are concentrated on the nitrogen atoms constituting the phenazine chromophore, the two carbons close to the positively charged nitrogen atoms and the two carbons which are in second position of the nitrogens still not charged in the phenazine group. These remarks were recorded for all studied molecules. Therefore, we record six radical attack reactive sites for each molecule with higher values for the uncharged nitrogen atoms constituting the phenazine chromophores. But for the remaining sites we record almost similar values lower than the values quoted before. From these findings, it is deduced that the sites most reactive to radical attacks by advanced oxidation are the neutral nitrogens of phenazine chromophores. So, there is a good match between the sites located experimentally and theoretically.
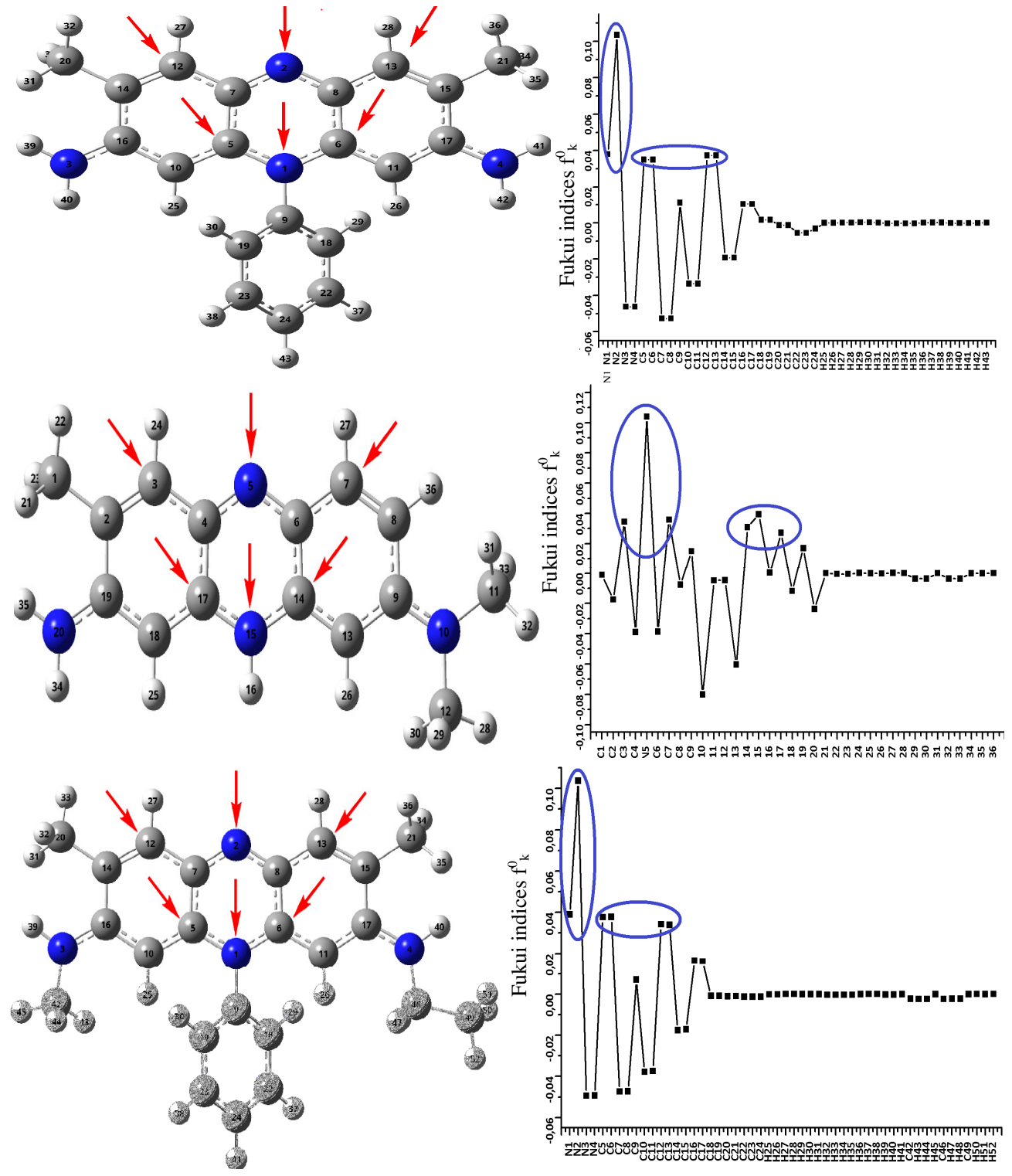

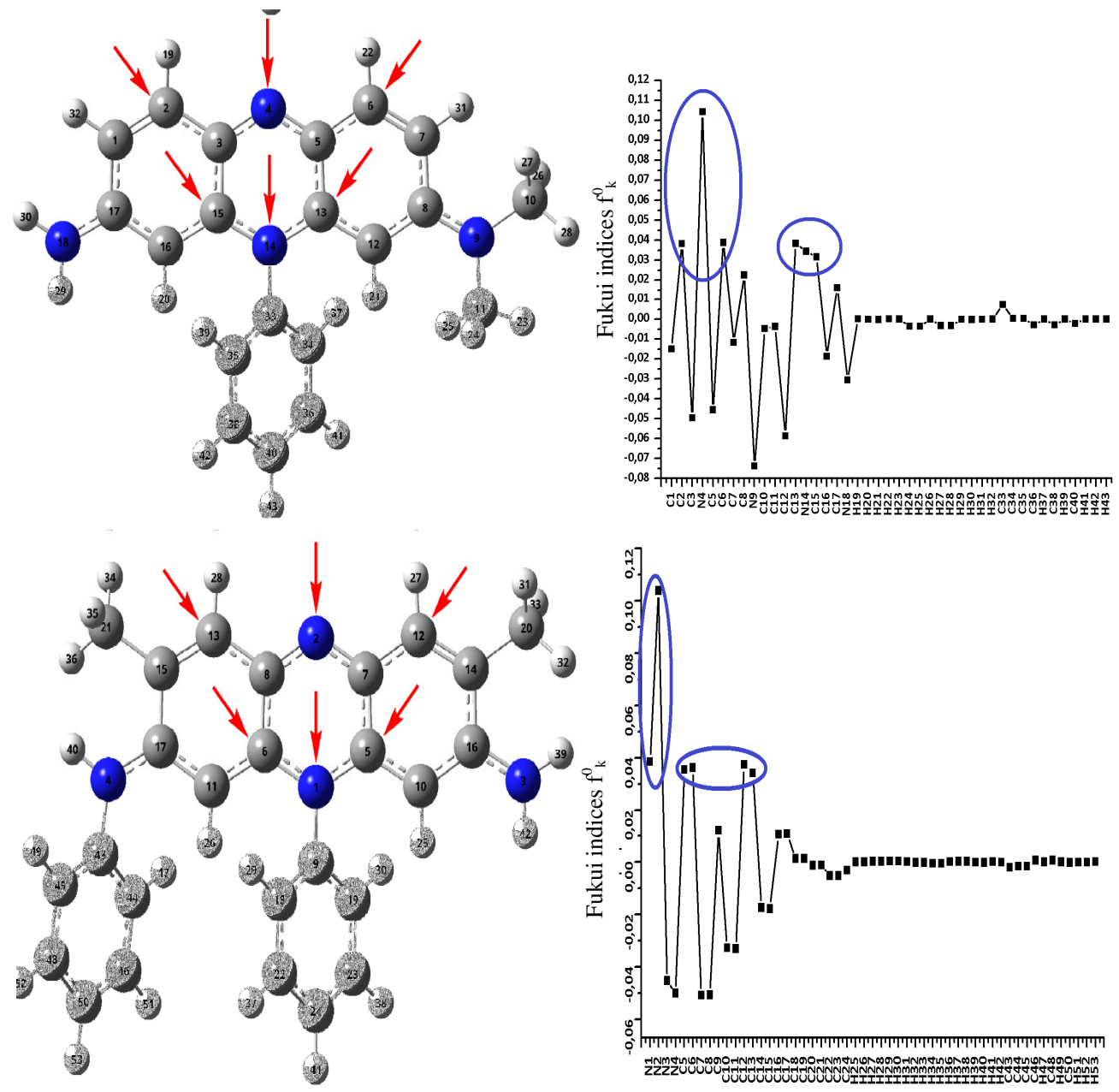

Figure 4. Fukui indices to radical attacks $f_{k}^{0}$ for the five molecules studied

In summary, the less stable basic dyes and the more solvated in water are the most profitable for radical attacks which leads to easy degradation except for an exception recorded for BV5 dye. The most reactive sites to radical attacks by advanced oxidation are the neutral nitrogens of the phenazine chromophores. Good agreement recorded between the results obtained experimentally and theoretically.

\section{Mulliken charges analysis}

In this analysis we will study the effects of grafted groups on the Mulliken charges of the six atoms most reactive to radical attacks. Hence, we calculated the Mulliken charges by the CAM-B3LYP functional and the $6-31++\mathrm{G}(\mathrm{d}, \mathrm{p})$ basis-set in the presence of water using the CPCM solvation model. The corresponding results are shown in the Table 3 . We also plotted the Mulliken charge curves versus atoms to determine the influence of these charges in each molecule. The corresponding curves are shown schematically in the Figure 5. 
Table 3. Atoms Mulliken charges most reactive to radical attacks for each molecule calculated by CAM-B3LYP / 6-31++G (d.p) in the presence of the water solvent by the CPCM solvation model. Numbers of atoms are shown in Figure 5

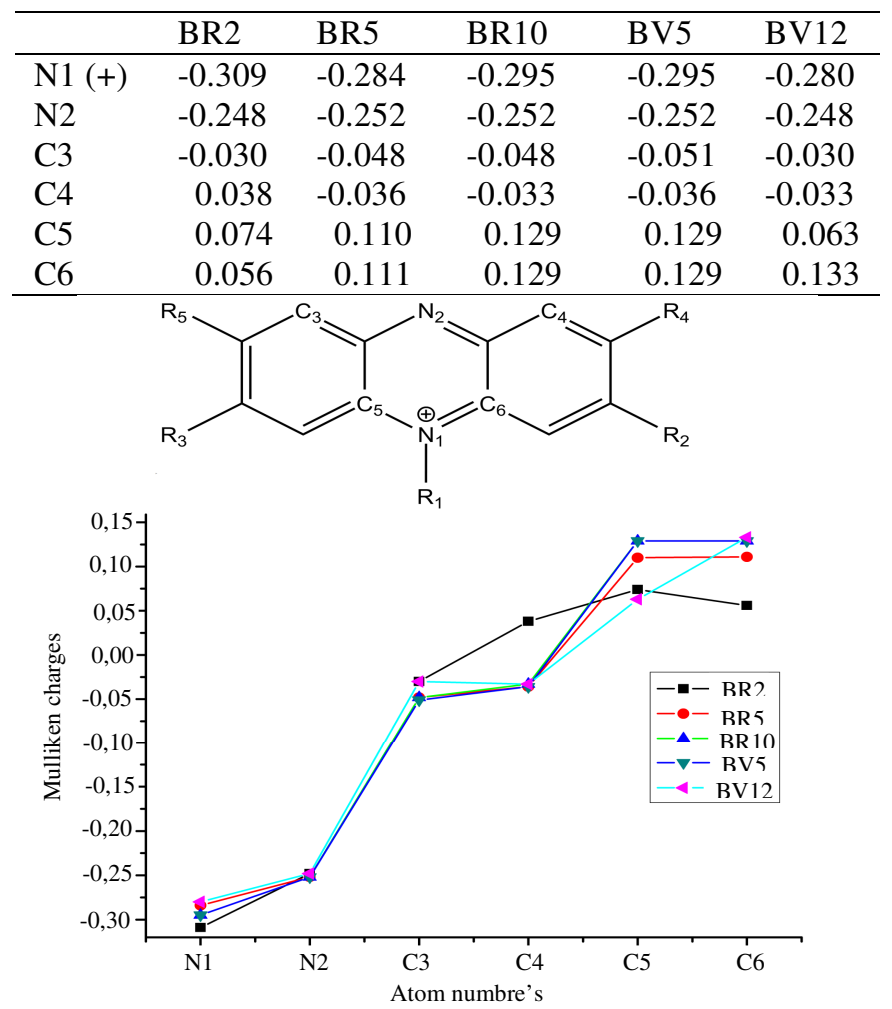

Figure 5. Atoms Mulliken charges most reactive to radical attacks for each molecule calculated by CAM-B3LYP / 6-31++G (d.p) in the presence of the water solvent by the CPCM solvation model

According to the Table 3, we find that the charges of the four atoms N1, N2, C3 and C4 are negative for all molecules, except an exception recorded for the charge of the $\mathrm{C} 4$ atom in the first column. The remaining atoms $\mathrm{C} 5$ and $\mathrm{C} 6$ are positive for all molecules. This phenomenon may be explained by the fact that the two $\mathrm{C} 5$ and $\mathrm{C} 6$ atoms are influenced by the attracting effect generated by the positively charged nitrogen atom which is nearby. We recorded this case for the five molecules. In addition, we see increases in top-down charges for the five molecules. Knowing that, we have classified the charges in ascending order. So, we notice that the corresponding orders obtained for the five molecules obey almost the same orders obtained in the Figure 4. From which, we deduce that the atoms with weaker charges are the most reactive to radical attacks.

In order to compare the charges of the five molecules, we have schematized the Figure 5. The latter shows that the charges of the $\mathrm{N} 2$ atoms of each molecule are almost identical. The same remarks were recorded for the two $\mathrm{C} 3$ and $\mathrm{C} 4$ atoms except for one exception that was recorded for the BR2 molecule. But the charges of the remaining atoms are different for the five molecules. This phenomenon shows that the three atoms N2, C3 and C4 are slightly influenced by the radicals grafted on the phenazine chromophore, perhaps because of their 
positioning. But the remaining atoms N1, C5 and C6 are more influenced by the grafted groups. Knowing that, the N2, C3 and $\mathrm{C} 4$ atoms are more influenced by radical attacks according to Figure 4. From which, we deduce that the atoms with Mulliken charges least influenced by the grafted groups are the most reactive to radical attacks.

We have also plotted the curve of the $\Delta f_{k}^{0}$ values as a function of the positive charges N1. This curve is shown schematically in the Figure 6 for the four molecules BR2, BR5, BR10 and BV12, because the BV5 molecule registered an exception and it was the same case for the Figure 3. Hence, we found proportionality between the two parameters quoted before with a regression coefficient in the order of 0.9722 . From which, we deduce that the increase of the atomic charge N1 improves the molecular susceptibility to radical attacks.

In summary, atoms with lower charges and less influenced by grafted groups are the most reactive to radical attack. The increase of the atomic charge N1 improves the molecular susceptibility to radical attacks.

\section{Transition states analysis}

This analysis is based on the study of the transition states of each molecule studied. The corresponding calculations were carried out by the CAM-B3LYP functional with the base $6-31++\mathrm{G}(\mathrm{d}, \mathrm{p})$ in the presence of water solvent by the solvation model CPCM. We used the TD-DFT method to determine the transition states with a convergence of $10^{-6}$ (convergence energy 1d-6). The parameters exploited according to these calculations are: excitation energies $\Delta \mathrm{E}_{\mathrm{H}-\mathrm{L}}$, dipole oscillator strengths $f$ and maximum wavelengths $\lambda_{\max }$. The corresponding results are shown in Table 4.

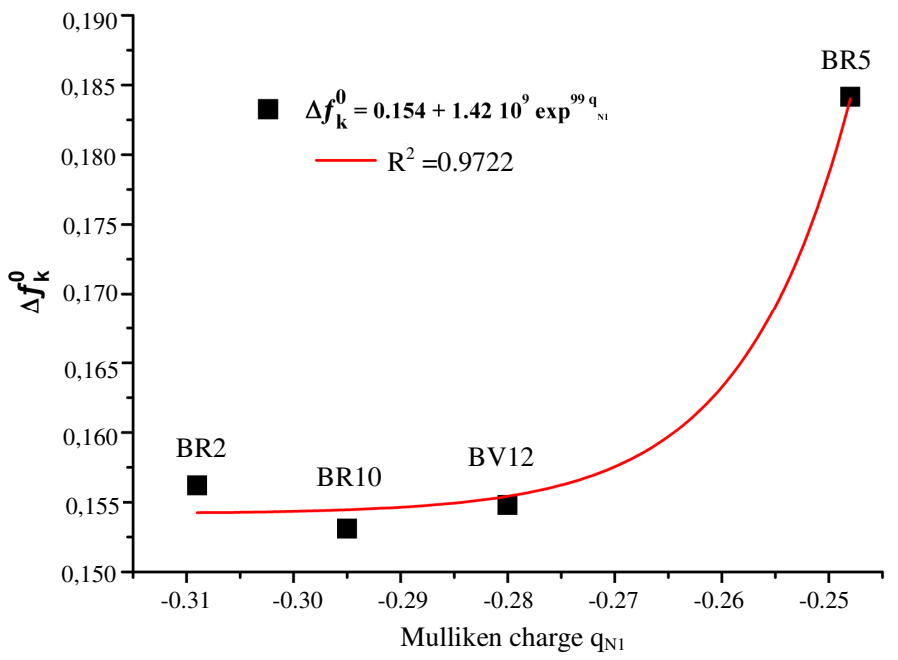

Figure 6. Relationship between Fukui indices $\Delta f_{k}^{0}$ and Mulliken charges $\mathbf{q}_{\mathbf{N} 1}$ of the four dyes BR2, BR5, BR10 and BV12 calculated by the functional CAM-B3LYP combined with the basis-set $6-31++\mathrm{G}(\mathrm{d}, \mathrm{p})$ in the presence of water solvent by the implicit solvation model CPCM

Dipole oscillator strengths reported on the Table 4 give the following order: $f$ (BV5) $\approx$ $f(\mathrm{BR} 5)<f(\mathrm{BR} 2)<f(\mathrm{BV} 12)<f(\mathrm{BR} 10)$. The maximum wavelengths give the following increasing order: $\lambda_{\max }(\mathrm{BR} 2)<\lambda_{\max }(\mathrm{BV} 12)<\lambda_{\max }(\mathrm{BR} 10)<\lambda_{\max }(\mathrm{BR} 5) \approx \lambda_{\max }$ (BV5). Knowing that, the increases in maximum wavelengths and oscillator strengths indicate Bathochromic $^{48,49}$ and Hyperchromic ${ }^{50}$ effects respectively. Hence, a bathochromic effect is 
recorded passing from the BR2 molecule to the BV5 molecule in the order obtained before. Hyperchromic effect is recorded passing from the BV5 molecule to the BR10 molecule according to the order of the oscillator strengths. We also note that the BR5 and BV5 molecules gave the highest maximum wavelengths and the lowest oscillator strengths compared to the other molecules with nearly identical values. This phenomenon may be explained by the fact that these two molecules have aimethylamine groups which have a very strong donor characters ${ }^{51,52}$. The remaining three molecules also have donor groups such as: ethylamine (BR10), phenylamine (BV12) and amine (BR2) but weak compared to the groups of the two molecules mentioned above. Hence, it is deduced that the donor groups influence the bathochrome and hyperchrome effect.

Table 4. Dipole oscillator strength $f$, transition energies $\Delta \mathrm{E}_{\mathrm{H}-\mathrm{L}}$ and maximum wave lengths $\lambda_{\max }$ calculated by TD-CAM-B3LYP/6-31++G(d.p) in the presence of the water solvent by the CPCM solvation model

\begin{tabular}{llllll}
\hline & BR2 & BR5 & BR10 & BV5 & BV12 \\
\hline$f$ & 0.7598 & 0.7267 & 0.8327 & 0.7233 & 0.8138 \\
$\Delta \mathrm{E}_{\mathrm{H}-\mathrm{L}}$ & 3.0190 & 2.9067 & 2.9315 & 2.9069 & 2.9774 \\
$\lambda_{\max }(1)$ & 410.07 & 426.54 & 422.94 & 426.52 & 416.42 \\
\hline
\end{tabular}

(1) $\lambda_{\max }$ were calculated by the following equation: $\lambda_{\max }=\frac{h c}{\Delta E_{H-L}}=\frac{1239.842017}{\Delta E_{H-L}}(\mathrm{~nm})$

We also plotted the curve of $\Delta f_{k}^{0}$ as a function of the dipole oscillator strengths $f$. This curve is shown schematically in the Figure 7 . From this figure, we notice an inverse proportionality between the two parameters $\Delta f_{k}^{0}$ and $f$ with a decreasing exponential rate which gave a regression coefficient in the order of 0.85748 . This phenomenon explains that the decrease of the molecular hyperchromic effect increases the profitability of degradation by radical attacks.

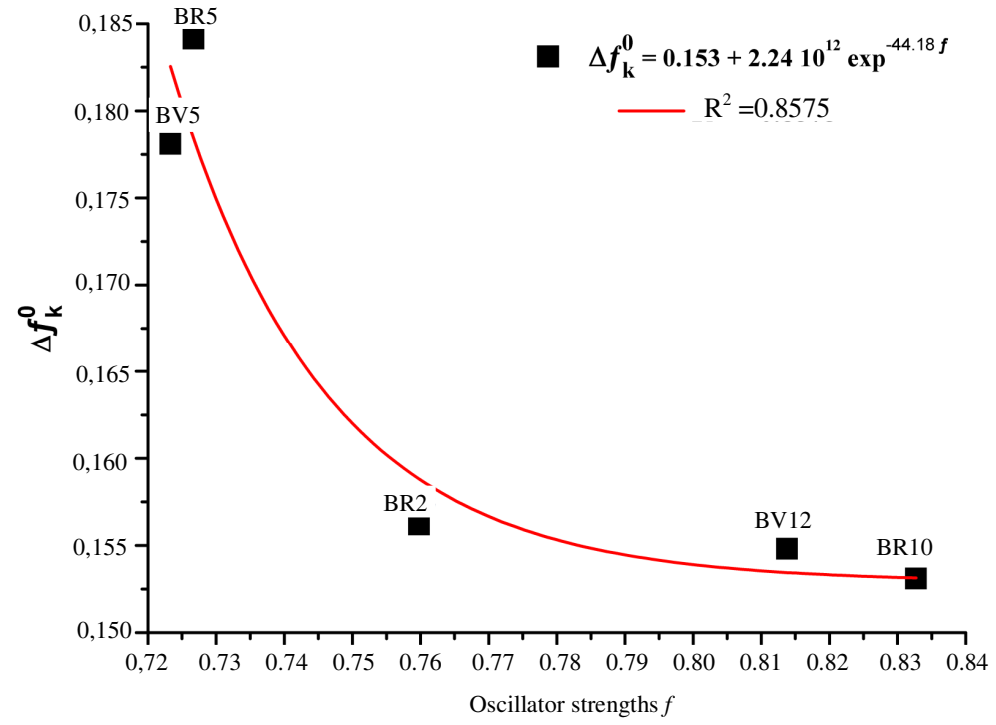

Figure 7. Relationship between Fukui indices $\Delta f_{k}^{0}$ and oscillator strengths $f$ of the five dyes studied calculated by the functional CAM-B3LYP combined with the basis-set $6-31++G(d, p)$ in the presence of water solvent by the implicit solvation model CPCM 
In summary, the bathochrome and hyperchromic effects are influenced by donor groups grafted onto the phenazine chromophore. The decrease of the molecular hyperchromic effect increases the profitability of degradation by radical attacks.

\section{Conclusion}

In this article we have described the parameters influencing molecular profitability to radical attacks. Hence, we focused on advanced oxidation field for the degradation of some basic dyes used in the textile industry. The studied dyes are: basic red 2, basic red 5, basic red 10 , basic violet 5 and basic violet 12 . The summaries obtained are as follows:

The stabilities of the molecules studied are influenced by the symmetry, the benzene and alkyl groups grafted onto the phenazine chromophore. The corresponding electronegativities are influenced by the strength of the positive charge centered on the nitrogen atom which is in turn influenced by the number and strength of donor groups grafted onto the phenazine backbone. The total dipole moments of the studied molecules are influenced by the groups located outside the XY plane. Finally, the solvation of these molecules is influenced by the number of alkyl groups grafted on the chromophore phenazine and amines.

The molecular instability of basic dyes increases their solvations in the presence of water and generates a higher profitability for radical attacks. The most reactive sites to radical attacks by advanced oxidation are the neutral nitrogens of the phenazine chromophores. Good agreement recorded between the results obtained experimentally and theoretically.

Atoms less influenced by the grafted groups with weaker Mulliken charges are the most reactive to radical attacks. The increase in the atomic charge N1 enhances the molecular susceptibility to the radical attacks.

The bathochrome and hyperchromic effects are influenced by donor groups grafted onto the phenazine chromophore. The decrease of the molecular hyperchromic effect increases the profitability of degradation by radical attacks.

Based on these summaries, we recommend experimentalist researchers to enhance advanced oxidation degradation profitability of the three BR2, BR10 and BV12 molecules, because of their $\Delta f_{k}^{0}$ low values relative to the two remaining molecules. Our proposal is based on the destruction of the molecular symmetry of the two BR2 and BV12 molecules by increasing the temperature or adding it to another solvent ${ }^{53}$. We also propose to increase the bathochromic effect for these three molecules by subjecting them to external electric fields ${ }^{54,55}$.

\section{References}

1. Moawed E A, El-Hagrasy M A and Farhat A A M, J Clean Prod., 2017, 157(20), 232-242; DOI:10.1016/j.jclepro.2017.04.145

2. Zhao C, Guo X, Ma J, Ge H, Jin L and Zhang Q, Comp Theo Chem., 2017, 1105(1), 89-96; DOI:10.1016/j.comptc.2017.02.027

3. Balanay M P and Kim D H, Comp Theo Chem., 2014, 1029, 1-12; DOI:10.1016/j.comptc.2013.12.005

4. Humelnicu I, Baiceanu A, Ignat M-E and Dulman V, Process Saf Environ Prot., 2017, 105, 274-287; DOI:10.1016/j.psep.2016.11.016

5. Anirudhan T S and Ramachandran M, Process Saf Environ Prot., 2015, 95, 215-225; DOI:10.1016/j.psep.2015.03.003 
6. Natarajan S, Bajaj H C and Tayade R J, J Environ Sci., 2018, 65, 201-222;

DOI:10.1016/j.jes.2017.03.011

7. El Haddad M, J Taibah Univ Sci., 2016, 10, 664-674;

DOI:10.1016/j.jtusci.2015.08.007

8. Buntić A V, Pavlović M D, Antonović D G, Šiler-Marinković S S and Dimitrijević-

Branković S I, J Clean Prod., 2017, 148(1), 347-354;

DOI:10.1016/j.jclepro.2017.01.164

9. Belaid K D, Kacha S, Kameche M and Derriche Z, J Envir Chem Eng., 2013, 1, 496503; DOI:10.1016/j.jece.2013.05.003

10. Bao X, Qin Z, Zhou T and Deng J, J Environ Sci., 2018, 65, 236-245;

DOI:10.1016/j.jes.2017.03.003

11. Gupta V K, Agarwal S, Olgun A, Demir H I, Yola M L and Atar N, J Ind Eng Chem., 2016, 34, 244-249; DOI:10.1016/j.jiec.2015.11.017

12. Liu Y, Fu J, Deng S, Zhang X, Shen F, Yang G, Peng H and Zhang Y, J Taiwan Inst Chem Eng., 2014, 45(5), 2480-2487; DOI:10.1016/j.jtice.2014.05.001

13. Moawed E A, Kiwaan H A and Elshazly M M, J Taiwan Inst Chem Eng., 2017, 80, 894-900; DOI:10.1016/j.jtice.2017.07.028

14. Trojanowicz M, Bojanowska-Czajka A, Bartosiewicz I and Kulisa K, Chem Eng J., 2018, 336, 170-199; DOI:10.1016/j.cej.2017.10.153

15. Boczkaj G and Fernandes A, Chem Eng J., 2017, 320, 608-633; DOI:10.1016/j.cej.2017.03.084

16. Nidheesh P V, Zhou M and Oturan M A, Chemosphere, 2018, 197, 210-227; DOI:10.1016/j.chemosphere.2017.12.195

17. Oulego P, Collado S, Laca A and Díaz M, Water Res., 2016, 88, 389-402; DOI:10.1016/j.watres.2015.09.048

18. Zheng L, Wang L, Liu Y, Guo C, Hou Y, Liu X and Zhang X, Colloids Surf A, 2018, 546, 83-90; DOI:10.1016/j.colsurfa.2018.03.007

19. Fathy N A, El-Shafey S E and El-Shafey O I, J Water Process Eng., 2017, 17, 95101; DOI:10.1016/j.jwpe.2017.03.010

20. Siwińska-Stefańska K, Fluder M, Tylus W and Jesionowski T, J Environ Manage., 2018, 212, 395-404; DOI:10.1016/j.jenvman.2018.02.030

21. Hassani A, Karaca C, Karaca S, Khataee A, Açıslı Ö and Yılmaz B, Ultrason. Sonochem., 2018, 42, 390-402; DOI:10.1016/j.ultsonch.2017.11.036

22. Singh R K, Babu V, Philip L and Ramanujam S, J Water Process Eng., 2016, 11, 118-129; DOI:10.1016/j.jwpe.2016.04.002

23. Ahmad T, Phul R, Alam P, Lone I H, Shahazad M, Ahmed J, Ahamad T and Alshehri S M, RSC Adv., 2017, 7, 27549-27557; DOI:10.1039/C6RA26888A

24. Carvalho H W P, Batista A P L, Hammer P and Ramalho T C, J Hazard Mater., 2010, 184, 273-280; DOI:10.1016/j.jhazmat.2010.08.033

25. Oliveira H S, Oliveira L C A, Pereira M C, Ardisson J D, Souza P P, Patrício P O and Moura F C C, New J Chem., 2015, 39, 3051-3058; DOI:10.1039/c4nj02063d

26. Houas A, Lachheb H, Ksibi M, Elaloui E, Guillard C and Herrmann J M, Appl Catal B Environ., 2001, 3, 1145-157; DOI:10.1016/S0926-3373(00)00276-9

27. Chaudhuri R G and Paria S, Dalt Trans., 2014, 4, 35526-5534; DOI:10.1039/C3DT53311E

28. Xia S, Zhang L, Pan G, Qian P and Ni Z, Phys Chem Chem Phys., 2015, 17, 53455351; DOI:10.1039/c4cp03877k 
29. Valiev M, Bylaska E J, Govind N, Kowalski K, Straatsma T P, van Dam H J J, Wang D, Nieplocha J, Apra E, Windus T L and de Jong W A, Comp Phys Commun., 2010, 181, 1477-1489; DOI:10.1016/j.cpc.2010.04.018

30. Yanai T, Tew D P and Handy N C, Chem Phys Lett., 2004, 393, 51-57; DOI:10.1016/j.cplett.2004.06.011

31. Barone V and Cossi M, J Phys Chem A, 1998, 102(11), 1995-2001; DOI:10.1021/jp9716997

32. Cossi M, Rega N, Scalmani G and Barone V, J Comp Chem., 2003, 24, 669-81; DOI:10.1002/jcc.10189

33. Elhorri A M and Zouaoui-Rabah M, Chin J Chem Eng., 2017, 25, 800-808; DOI:10.1016/j.cjche.2016.09.001

34. Elhorri A M, Belaid K D, Zouaoui-Rabah M and Chadli R, Comp Theo Chem., 2018, 1130, 98-106; DOI:10.1016/j.comptc.2018.03.018

35. Zouaoui-Rabah M, Sekkal-Rahal M, Djilani-Kobibi F, Elhorri A M and Springborg M, J Phys Chem A, 2016, 120, 8843-8852; DOI:10.1021/acs.jpca.6b08040

36. Janjua M R S A, Jamil S, Ahmad T, Yang Z, Mahmood A and Pan S, Comp Theo Chem., 2014, 1033, 6-13; DOI:10.1016/j.comptc.2014.01.031

37. Fink R F, Pfister J, Zhao H M and Engels B, Chem Phys., 2008, 346, 275-285; DOI:10.1016/j.chemphys.2008.03.014

38. Marenich A V, Cramer C J and Truhlar D G, J Phys Chem B, 2009, 113(18), 63786396; DOI:10.1021/jp810292n

39. Bauernschmitt R and Ahlrichs R, Chem Phys Lett., 1996, 256, 454-464; DOI:10.1016/0009-2614(96)00440-X

40. Casida M E, Jamorski C, Casida K C and Salahub D R, J Chem Phys., 1998, 108, 4439-4449; DOI:10.1063/1.475855

41. Wang S-J, Wang Y-F and Cai C, J Phys Chem C, 2015, 119, 16256-16262; DOI:10.1021/acs.jpcc.5b04656

42. Parr R G and Yang W, Density Theory for atoms and Molecules, Oxford University Press: Oxford, 1989.

43. Parr R G, Szentpaly L V and Liu S, J Am Chem Soc., 1999, 122, 1922-1924; DOI:10.1021/ja983494x

44. Yang W T and Mortier W J, J Am Chem Soc., 1986, 108, 5708-5711; DOI:10.1021/ja00279a008

45. Reyes A, Cuervo P A, Orozco F, Abonia R, Duque-Noreña M, Pérez P and Chamorro E, J Mol Model., 2013, 19, 3611-3618; DOI:10.1007/s00894-013-1893-X

46. Alcoba D R, Lain L, Torre A, Oña O B and Chamorro E, Phys Chem Chem Phys., 2013, 15, 9594-9604; DOI:10.1039/C3CP50736J

47. Chattaraj P K and Sengupta S, J Phys Chem A, 1999, 103, 6122-6126; DOI:10.1021/jp990242p

48. Shariati S and Pakiari A H, Comp Theo Chem., 2017, 1099, 92-101; DOI:10.1016/j.comptc.2016.11.015

49. Aydin M and L.Akins D, Comp Theo Chem., 2018, 1132, 12-22; DOI:10.1016/j.comptc.2018.04.004

50. Gurav N D, Gejji S P and Pathak R K, Comp Theo Chem., 2018, 1138, 23-38; DOI:10.1016/j.comptc.2018.05.018

51. Islam M M, Bhuiyan M D H, Bredow T and Try A C, Comp Theo Chem., 2011,967, 165-170; DOI:10.1016/j.comptc.2011.04.012 
52. Marcano E, Squitieri E, Murgich J and Soscún H, Comp Theo Chem., 2012, 985, 72 79; DOI:10.1016/j.comptc.2012.02.001

53. Wang Z D, Yoshida M and George B, Comp Theo Chem., 2013, 1017, 91-98;

DOI:10.1016/j.comptc.2013.05.007

54. Waskasi M M, Hashemianzadeh S M and Sarhangi O M, Comp Theo Chem., 2011, 978, 33-40; DOI:10.1016/j.comptc.2011.09.029

55. Javan M B, Phys Lett A, 2012, 376, 3241-3247; DOI:10.1016/j.physleta.2012.07.040 